\title{
Physical control of zooplankton distribution at the Strait of Gibraltar during an episode of internal wave generation
}

\author{
D. Macíass ${ }^{1,2 *}$, R. Somavilla ${ }^{3}$, J. I. González-Gordillo ${ }^{4,5}$, F. Echevarría ${ }^{1,5}$ \\ ${ }^{1}$ Departamento de Biología, Facultad de Ciencias del Mar y Ambientales, Universidad de Cádiz, 1150 Cádiz, Spain \\ ${ }^{2}$ Integrative Oceanography Division, Scripps Institution of Oceanography, University of California, San Diego, La Jolla, \\ California 92037, USA \\ ${ }^{3}$ Centro Oceanográfico de Santander, Instituto Español de Oceanografía, Promontorio de San Martin s/n, 39080 Santander, Spain \\ ${ }^{4}$ Centro Andaluz de Ciencia y Tecnología Marina (CACYTMAR), Universidad de Cádiz, 11510 Cádiz, Spain \\ ${ }^{5}$ Unidad Asociada de Oceanografía Interdisciplinar UCA-CSIC, 11510 Cádiz, Spain
}

\begin{abstract}
We analyzed the effect of physical forcing on zooplankton biomass distribution in the Strait of Gibraltar as a function of tidal phase. A set of 5 Longhurst-Hardy-Plankton-Recorder (LHPR) casts were made along the main channel of the Strait during different phases of the tidal cycle to determine how the hydrological processes taking place in the strait (mainly internal wave generation) influenced the distribution and taxonomic composition of zooplankton biomass. A CTD coupled to the LHPR net allowed a detailed study of the hydrological patterns created by the generation and development of the internal waves. Plankton samples were analyzed using a semi-automatic method for zooplankton discrimination (plankton visual analyzer) which is able to differentiate each individual within a sample into specific taxonomic groups. The results show that the internal wave generation on the main channel of the strait induces divergent processes causing a reduction of the zooplankton biomass. Flow patterns within the internal waves lead to alternating bands of high and low zooplankton biomass with varying taxonomic composition. Changes in taxonomic composition appear to be the result of spatial differentiation between smaller (weak-swimming) and larger (strong-swimming) taxa. This work demonstrates the necessity to consider and understand physical processes when addressing biological patterns, especially in regions with intense hydrodynamic regimes.
\end{abstract}

KEY WORDS: Strait of Gibraltar · Internal waves · Physical forcing · Zooplankton distribution

\section{INTRODUCTION}

Physical forcing of biogeochemical features is a constant throughout the oceans of the world, but this effect is especially evident in certain regions where there are topographic constrictions. These constrictions interact with the dominant hydrological conditions (e.g. tides, currents, winds) to create a powerful physical environment which can drive biogeochemical patterns.

For example, the Strait of Gibraltar has strong tidally induced currents and severe topographic constrictions.
Average along-strait circulation presents a 2-layer, inverse-estuarine pattern with a surface inflow of Atlantic waters (Surface Atlantic Water [SAW] and North Atlantic Central Waters [NACW]) and a deep outflow of Mediterranean waters (Mediterranean Outflowing Water [MOW]; Gascard \& Richez, 1985), the inflow being around $5 \%$ greater in order to compensate for evaporative losses. This 2-layer circulation gives rise to differences in the characteristics of the along-strait direction; for example, from the middle section eastwards, the surface layer always flows into 
the Mediterranean (García-Lafuente et al. 2000), whereas in the western section of the Strait this layer can reverse its flow direction at certain times in the tidal cycle when tidal amplitude is sufficiently large (Macías et al. 2007).

There are significant differences in tidal amplitude between the western and eastern parts of the strait, and this induces barotropic and baroclinic tidal currents along the main channel (Lacombe \& Richez 1982) that are 4 times greater in magnitude than the time-averaged flow (García-Lafuente \& VargasDomínguez 2003). The baroclinic flow enhances the vertical velocity shear and, hence, generates more interfacial mixing, which fertilizes the upper water column (Macías et al. 2007). Moreover, the bottom topography of the strait presents prominent features such as a main sill on the western side (Camarinal Sill), which lifts the seabed from nearly $800 \mathrm{~m}$ to only $250 \mathrm{~m}$ depth. Tidal currents, the conjunction of 3 water masses and severe topography together create a very complicated hydrologic pattern (Parrilla 1990) that includes internal wave generation (Armi \& Farmer 1988, Bruno et al. 2002) and horizontal surface divergences (Izquierdo et al. 2001, Macías et al. 2007). These processes have a considerable influence on the biogeochemical budget of the Mediterranean Sea (Minas et al. 1991, Macías et al. 2006) since this strait constitutes its only connection with the Atlantic Ocean.

The effect of hydrological structures on the distribution and dynamics of biogeochemical elements have been described in several studies dealing with the temporal composition of the incoming Atlantic Jet (Gómez et al. 2004, Macías et al. 2006) and with spatial patterns within the strait itself (Echevarría et al. 2002, Macías et al. 2008). In this context, the strait has been described as an intermittent pump. This is because both interfacial mixing, provoked by the internal waves (Macías et al. 2007), and the rise to the surface of nutrient-rich waters (i.e. the NACW) forced by the mean along-strait flux (Gómez et al. 2001, Macías et al. 2008) induce upwelling phenomena over the Camarinal Sill with a tidal-related periodicity.

Researchers have previously reported the dependence of the composition of the incoming Atlantic waters with the tidal phase on intrusion of chlorophyll-rich patches concurrent with the presence of internal waves at the interface between Atlantic and Mediterranean waters (Macías et al. 2006). The vertical structure of the deep chlorophyll maximum (DCM) also depends on tidal forcing. For example, Macías et al. (2008) found at least 3 different kinds of DCM associated with specific water mass interfaces, each with different origins and biogeochemical characteristics.
However, almost all previous studies in this strait dealing with interactions due to physical-biological linkage refer exclusively to distribution of nutrients and phytoplankton, with little research on higher trophic levels. One of the first studies researching the zooplankton distribution in this region was conducted by Frassetto et al. (1961), who used sound scattering to study the diel vertical migration (DVM) pattern in the area. More recently, Gómez et al. (2000) and Echevarría et al. (2002) reported microzooplankton abundance data at a number of stations within the channel of the strait. However, analyses were limited to microzooplankton biomass distribution, with no discussion of specific composition.

Zooplankton are considered to comprise a key link between trophic levels because they constitute the main carbon transfer pathway within the marine food web (Mann \& Lazier 1991). Therefore, the study of zooplankton distribution due to forcing from meteorological and hydrological conditions has become one of the key objectives in international research programs (i.e. GLOBEC). It is particularly important to address these issues in the Strait of Gibraltar due to: (1) the strong influence of the hydrological conditions on biogeochemical patterns, and (2) the relatively high abundance of top predators (such as tuna and marine mammals), which should imply a substantial transfer of organic matter up through the food web.

Internal waves in the strait are potentially important to secondary producers because they can cause upwelling and aggregate particles, prey and the organisms themselves. These effects are particularly important at the zooplankton trophic level (Lennert-Cody \& Franks 1999). These processes are responsible for the periodic formation of aggregation of biomass (Haury et al. 1979), giving rise to zooplankton hotspots; these are defined as regions of the ocean where, recurrently, zooplankton biomass is well above the average (Marine Zooplankton Colloquium 2 2001). The aggregated distributions at intermediate trophic levels are of great importance for carbon transfer in the food web, because food becomes more available for high predators (as it is more easily located and captured) while the same average concentration is maintained (Valiela 1995).

In the present study we investigated: (1) the spatial distribution of the zooplankton community within the main channel of the Strait of Gibraltar and (2) how it is forced by the main hydrological processes. For this we used a series of Longhurst-Hardy Plankton Recorder (LHPR) net casts. The patterns observed are discussed in the framework of the hydrodynamic conditions (including tides and internal waves) in order to give an informed description of the effects of physical mechanisms on biological distributions. 


\section{MATERIALS AND METHODS}

Sampling strategy. Zooplankton were sampled using an LHPR, which is a multiple sampling net designed for plankton capture that becomes narrower in its front part with a nose cone on which a plankton gauze is mounted (Wiebe \& Benfield 2003). Samples were analysed using software for plankton determination known as a plankton visual analyzer (PVA) (developed by the Marine Research Division of AZTI; Boyra et al. 2005) which counts and measures plankton organisms. The PVA was combined with a classification algorithm based on the use of the Fisher functions (Krzanowski 1998) to provide a semi-automatic method for counting, measuring and classifying zooplankton.

The LHPR was fitted with a $200 \mu \mathrm{m}$ mesh net and programmed with a gauze advance time of $4 \mathrm{~min}$ (2 min for the fifth sampling). During each haul the net was towed at a speed of 3 knots $\left(1.5 \mathrm{~m} \mathrm{~s}^{-1}\right)$ or less, for approximately $2 \mathrm{~h}$. The volume filtered by the net was recorded by a flow-meter mounted within the nose cone. The LHPR was also equipped with a CTD SBE-19 and fluorometer sensor that registered pressure, temperature, salinity and fluorescence of the water masses as the LHPR passed. This design allows a large number of samples to be obtained in a single haul (between 30 and 60 ), and is able to resolve partially the variability of zooplankton distribution at a short scale and the aggregation phenomena that were expected to occur in the strait. A series of 5 casts with the LHPR net was made along the main channel of the Strait of Gibraltar (Fig. 1) during a cruise performed on board the BIO 'Hespérides' in November 2003. The first 4 casts were carried out following a variable depth strategy (undulating between $150 \mathrm{~m}$ depth and surface) with an aver- age veer (descent)/haul (ascent) rate of $0.3 \mathrm{~m} \mathrm{~s}^{-1}$. The fifth cast was performed following a different strategy whereby the net was deployed at a constant depth (approx. $100 \mathrm{~m}$ ) by keeping the vessel velocity and the haul wire length constant.

Fig. 2 shows the tidal conditions over the Camarinal Sill during each cast. The first 3 casts were carried out before the appearance of internal waves and in the eastern sector of the strait (at some distance of the Camarinal Sill, Fig. 1), so we did not expect the internal waves to affect zooplankton distribution during these initial casts. We performed Casts 4 and 5 over the Camarinal Sill (Fig. 1) just before (Cast 4) and after (Cast 5) the generation of internal waves (Fig. 2). During Cast 4, the tidal current changed from eastward to westward, and the cast finished shortly after the lowwater time. Tidal currents were towards the west during the entire period of Cast 5, since it coincided with the tidal phase when the internal waves were developed over the Camarinal Sill. This cast ended just before the high-water time, when these waves are typically released (Fig. 2, Table 1).

After each cast, the LHPR net was hauled to the vessel to collect, preserve and identify the plankton samples. The gauze was inspected and cut so that each sample correlated to its position within the water column during towing, and was then preserved in a $4 \%$ formalin solution in a storage cup until analysis at the laboratory. The first and last samples (corresponding to net deployment and retrieval phases) of each cast were discarded.

Sample analysis. Plankton biomass was determined using wet weight by filtering the sample through a $200 \mu \mathrm{m}$ net. This is a quick and non-destructive method for estimating biomass. After biomass determination, the samples were returned to the storage cups for subsequent analysis.

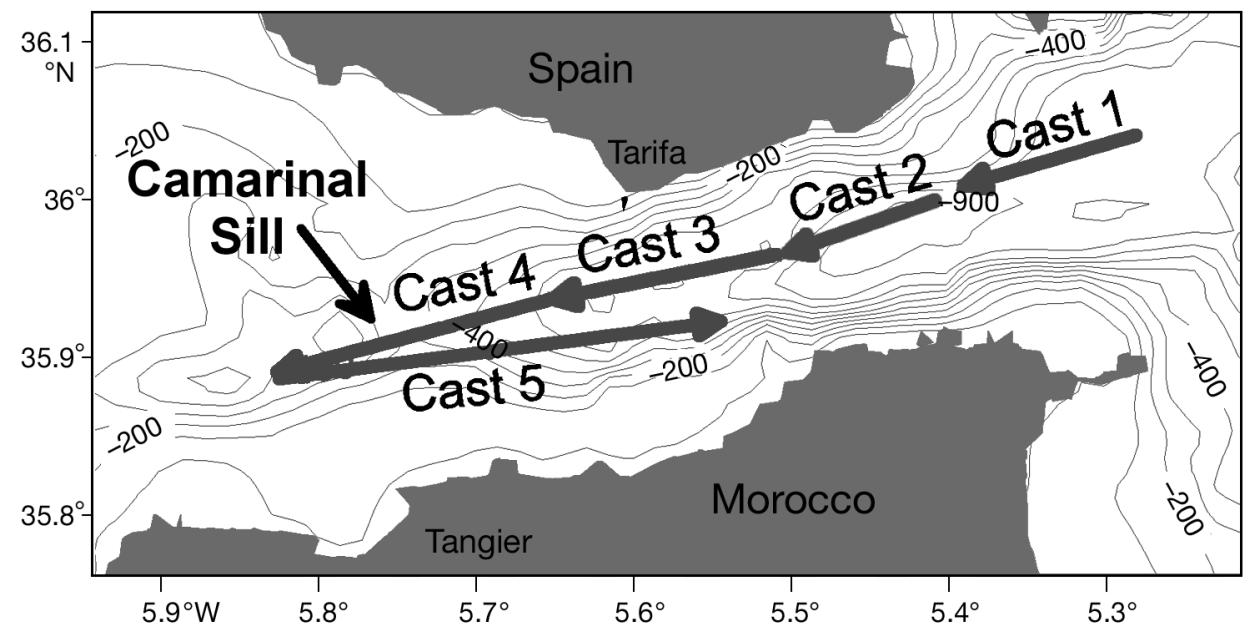

Fig. 1. Sampling paths along the Strait of Gibraltar and position of the main sill of the strait (Camarinal Sill). Contour lines: isobaths at $100 \mathrm{~m}$ intervals 
Table 1. Number of samples analyzed, initial and final position, time (date) and water depths in each cast

\begin{tabular}{|c|c|c|c|c|c|c|c|c|c|c|c|}
\hline \multirow[t]{2}{*}{ Cast } & \multirow{2}{*}{$\begin{array}{c}\text { Plankton } \\
\text { samples (n) }\end{array}$} & \multicolumn{2}{|c|}{ — Initial position — } & \multicolumn{2}{|c|}{ — Final position — } & \multicolumn{2}{|c|}{ — Time $(\mathrm{h})$ - } & \multicolumn{3}{|c|}{ - Depth $(\mathrm{m})-$} & \multirow{2}{*}{$\begin{array}{c}\text { Water } \\
\text { depth }(\mathrm{m})\end{array}$} \\
\hline & & Latitude & Longitude & Latitude & Longitude & Start & Finish & Max & Min & Mean & \\
\hline 1 & 32 & $36^{\circ} 02^{\prime} 53^{\prime \prime}$ & $-5^{\circ} 18^{\prime} 22^{\prime \prime}$ & $36^{\circ} 01^{\prime} 13^{\prime \prime}$ & $-5^{\circ} 24^{\prime} 32^{\prime \prime}$ & $23: 00^{\mathrm{a}}$ & $01: 00^{\mathrm{b}}$ & 183.8 & 20.1 & 89.8 & 800 \\
\hline 2 & 32 & $36^{\circ} 00^{\prime} 34^{\prime \prime}$ & $-5^{\circ} 26^{\prime} 57^{\prime \prime}$ & $35^{\circ} 58^{\prime} 46^{\prime \prime}$ & $-5^{\circ} 33^{\prime} 50^{\prime \prime}$ & 02:08 & $04: 27$ & 146.7 & 18.1 & 80.41 & 600 \\
\hline 3 & 36 & $35^{\circ} 58^{\prime} 43^{\prime \prime}$ & $-5^{\circ} 33^{\prime} 48^{\prime \prime}$ & $35^{\circ} 58^{\prime} 02^{\prime \prime}$ & $-5^{\circ} 39^{\prime} 15^{\prime \prime}$ & 05:15 & $07: 43$ & 150.2 & 13.8 & 61.24 & 600 \\
\hline 4 & 36 & $35^{\circ} 55^{\prime} 33^{\prime \prime}$ & $-5^{\circ} 39^{\prime} 50^{\prime \prime}$ & $35^{\circ} 53^{\prime} 01^{\prime \prime}$ & $-5^{\circ} 48^{\prime} 36^{\prime \prime}$ & 08:15 & $10: 45$ & 154 & 13.8 & 46.09 & 300 \\
\hline 5 & 77 & $35^{\circ} 55^{\prime} 13^{\prime \prime}$ & $-5^{\circ} 50^{\prime} 10^{\prime \prime}$ & $35^{\circ} 55^{\prime} 24^{\prime \prime}$ & $-5^{\circ} 35^{\prime} 34^{\prime \prime}$ & $11: 43$ & $16: 06$ & 116.6 & 89.2 & 104.04 & 400 \\
\hline
\end{tabular}

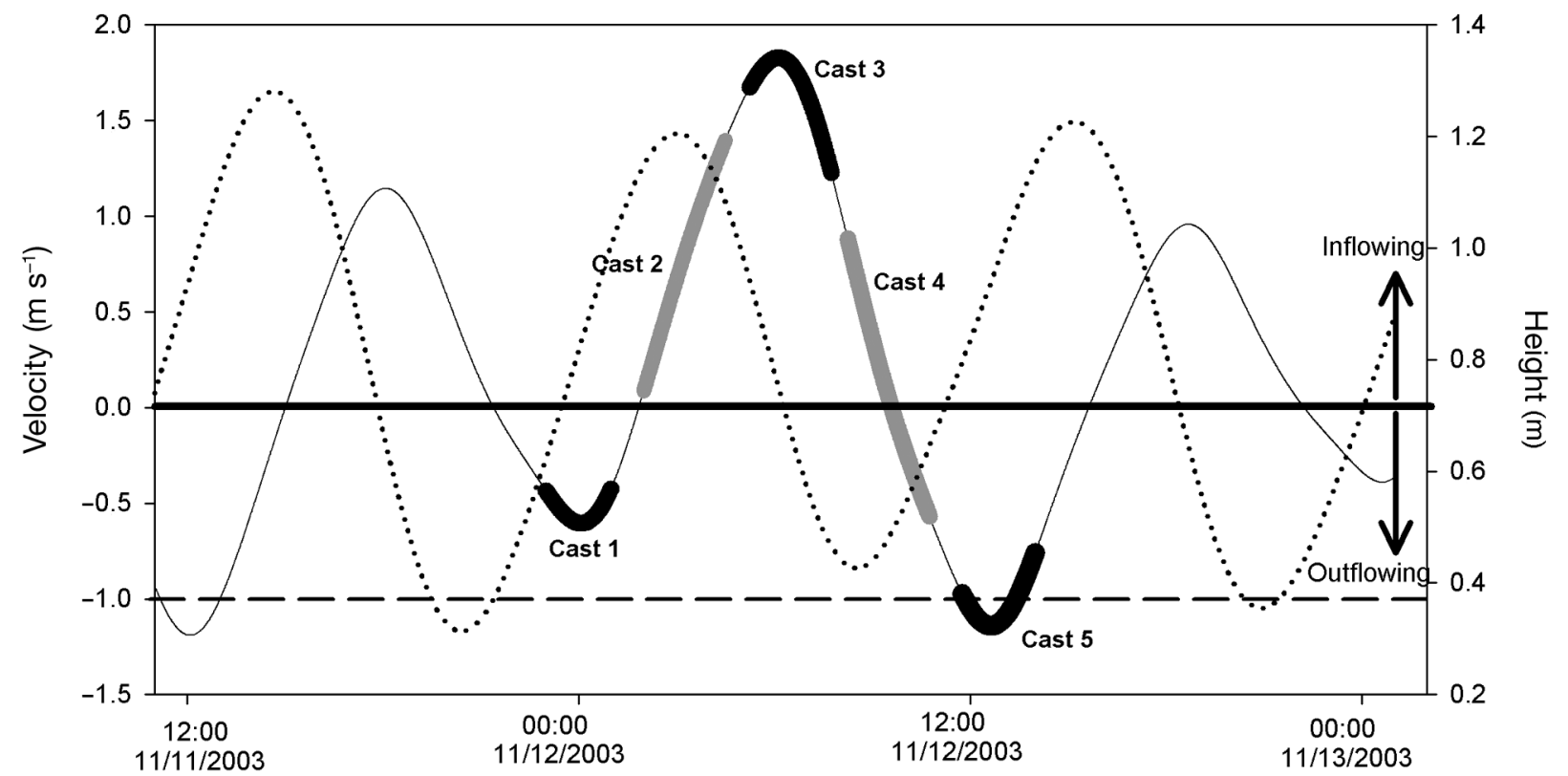

Time and date $(\mathrm{mo} / \mathrm{d} / \mathrm{yr})$

Fig. 2. Tidal conditions over the Camarinal Sill (along-strait current velocity and tidal height) during the sampling period. Solid curve: current velocity over the sill (positive values are westward). Dotted line: tidal height at Tarifa Harbor. Horizontal dashed

line: minimum out-flowing velocity for the generation and liberation of internal waves (according to Vázquez et al. 2008)

Abundance and biovolume (total, as well as for each taxonomic group) were also estimated for each sample. These estimates were made by counting and measuring each plankton organism in the sample using the PVA. The complete semi-automatic procedure for analyzing the plankton samples involves 4 steps: acquisition of digital images, counting, measuring and classification.

A good methodology for image acquisition and sample staining is initially necessary to enhance contrast between plankton organisms and the surrounding water, which enables a better determination of morphometric characteristics. Samples were stained with $1 \%$ Bengala Pink (which selectively stains lipids) for $24 \mathrm{~h}$. To avoid problems with optical magnification, organisms from each sample were sorted into 2 fractions: larger than and smaller than $1000 \mu \mathrm{m}$. Both frac- tions were placed in Petri dishes and scanned using a high-definition scanner with a minimum resolution of 600 and 1200 dots per inch for the larger and smaller fractions, respectively.

Next, organisms were counted within each sample using the scanned image. This process was done by PVA using a threshold colour level which distinguishes organisms from the background values. Simultaneously, various morphometric characteristics of each individual were recorded and stored. The main characteristics measured were area, perimeter and diameter, from which a set of derived measures such as biovolume could be obtained.

Finally, the morphometric characteristics measured by the PVA enabled the identification of individuals when introduced into the classification algorithm based on the use of Fisher functions. The Fisher func- 
tions applied in the algorithm were obtained by applying a discriminant analysis to a set of 3564 zooplankton organisms whose taxonomic group was known previously. Discriminant analysis is a multivariate statistical technique applied to identify the characteristics that differentiate among the members of 2 or more groups, and to create a set of functions (Fisher functions) able to differentiate members of one group from another, with the maximum possible precision (Krzanowski 1998). Individual Fisher functions were obtained to distinguish each group. In this case, the main taxonomic groups discriminated were copepods, decapod and euphausiid larvae, ostracods, cladocerans, chaetognaths, siphonophores, salps, larvaceans, barnacle larvae, mysids, annelids, isopods, amphipods, mollusc larvae and fish larvae. Individuals were classified into these taxonomic groups for only 3 of the 5 casts: Cast 2, representing the nighttime and eastern sector casts, and Casts 4 and 5, conducted over the Camarinal Sill.

\section{RESULTS}

\section{Casts 1, 2 and 3}

Temperature and salinity records (Fig. 3) revealed the presence of the Atlantic Jet (AJ) at the surface (fresher and warmer waters) and MOW in the deep layers. The Atlantic-Mediterranean Interface (AMI) in this area is usually associated with the 37 isohaline (shown as a thicker isohaline in Fig. 3b) and occurred at progressively greater depths towards the Atlantic (i.e. from Cast 1 to Cast 3). Superimposed on this tendency, some shorter oscillations of the AMI vertical position propagating into the Mediterranean Basin were observed at the start of Cast 1 (Fig. 3).

The chlorophyll distribution showed very low values ( 0.2 to $0.4 \mathrm{mg} \mathrm{m}^{-3}$ ) associated with the surface AJ, while higher values appeared to be related to water mass interfaces, mainly to the SAW-NACW interface (thicker isotherm $\left[17.5^{\circ} \mathrm{C}\right]$ in Fig. 3a). During Cast 1, maximum chlorophyll values $\left(>1.5 \mathrm{mg} \mathrm{m}^{-3}\right.$ ) were found coincident with variation in the depth of the AMI in the easternmost part of the cast. During Casts 2 and 3, maximum chlorophyll values were observed coincident with the SAW-NACW interface position (Fig. 3c).

Two zooplankton biomass maxima were found for Cast 1 at different depths in the eastern sector of the strait (Fig. 3d), the shallower one coincident with the chlorophyll maximum associated with the variation in AMI depth, and the deeper at a depth of around $100 \mathrm{~m}$. Mean zooplankton biomass in this cast was the highest of all the records (Table 2) and tended to decrease towards the west, in line with decreasing chlorophyll concentrations.
In Cast 2, mean zooplankton biomass was lower than in the other 2 nighttime casts (Table 2), although the difference among these casts was not significantly different (ANOVA, $F=1.3, \mathrm{p}>0.05$ ). Further, mean zooplankton biomass did not seem to show so conspicuous a relationship with either hydrological or biogeochemical variables as in Casts 1 and 3 (Fig. 3d).

Finally, during Cast 3, mean zooplankton biomass values increased again with respect to that found in Cast 2 (Table 2), especially at the start and the end of the sampling period (left-hand side of Fig. 3). There was a visual spatial relationship between chlorophyll and zooplankton at the beginning of the cast (Fig. 3c,d), with maximum zooplankton biomass coincident with the highest chlorophyll concentration. However, at the end of the cast, maximum zooplankton concentrations were found at much shallower depths than the chlorophyll maxima within the SAW.

Zooplankton taxonomic composition was analyzed only in Cast 2. The 12 most abundant taxonomic groups (Tables 3-5) were selected from the complete set offered by the automatic classification system (see above), as the rest were scarcely present in the analysed samples. In these tables, individual abundances are presented for the different sectors of each cast (as defined previously) as well as the mean total abundance in each cast.

The mean taxonomic composition of Cast 2 (taken as representative of the eastern section of the strait and of night conditions) is presented in Fig. $4 \mathrm{a}, \mathrm{b}$ for the 2 analysed size fractions. Samples from this cast have been divided into 2 groups - surface $(<30 \mathrm{~m})$ and deep $(>120 \mathrm{~m})$ - in order to analyse possible differences induced by the DVM pattern (Table 3). The first impression from the sample data of this cast is that there are very few differences between surface and deep samples; both have a very similar composition in terms of taxonomic groups identified and in their percentage distribution between the 2 size fractions.

In the smaller fraction $(<1000 \mu \mathrm{m})$, copepods dominated the community, especially medium copepods, and ostracods were the second most abundant (Fig. 4a, Table 3). However, in the larger fraction (>1000 $\mu \mathrm{m})$, greater diversity was found (Fig. 4a), as well as larger differences between surface and deep samples (Table 3).

In both sample groups (surface and deep), the dominant taxa in this larger fraction were large copepods (17\% in surface, $32 \%$ in deep) and chaetognaths (18\% in surface and $50 \%$ in deep). However, surface samples were more diverse, with higher number of different groups more uniformly distributed (note that large copepods and chaetognaths account for $82 \%$ of the abundance in deep-water samples, while they account for $32 \%$ in surface water samples), euphausiids and 


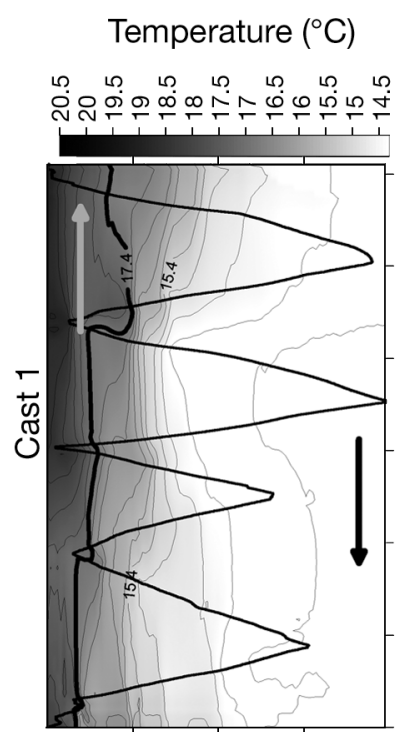

Salinity

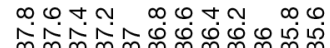
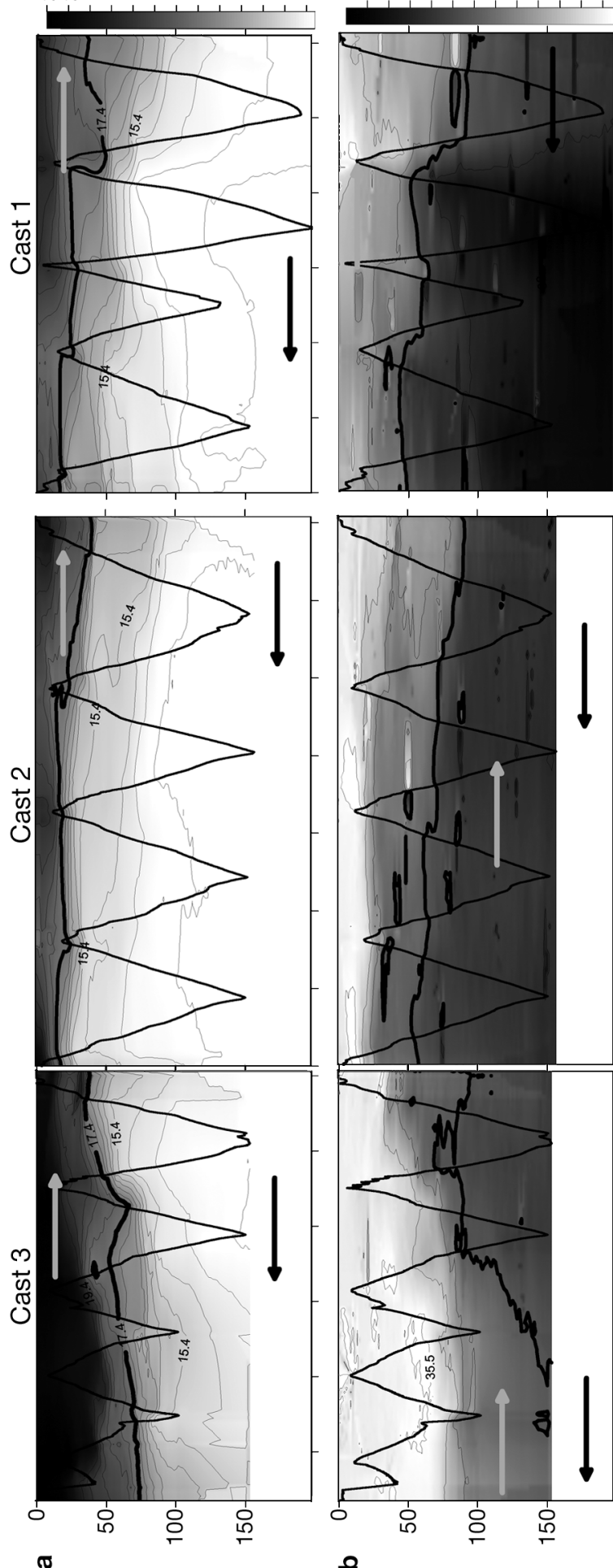

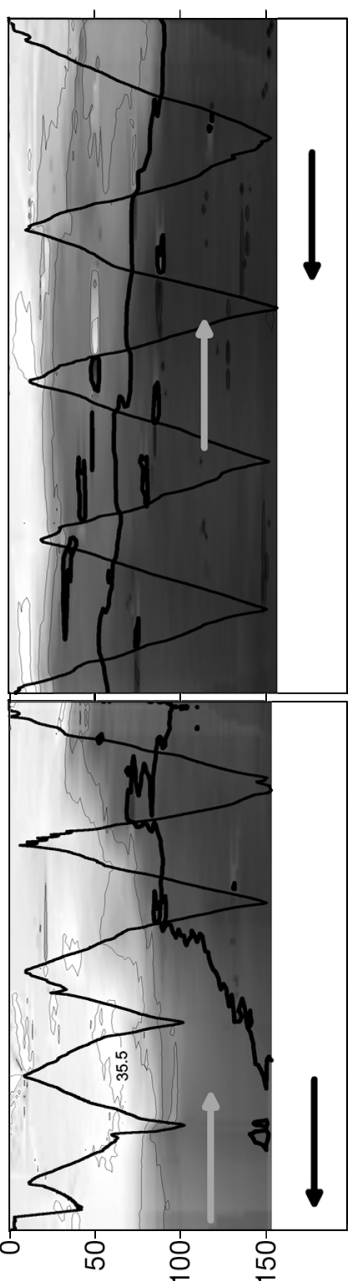

○
Chlorophyll a $\left(\mathrm{mg} \mathrm{m}^{-3}\right)$

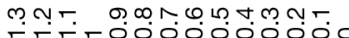
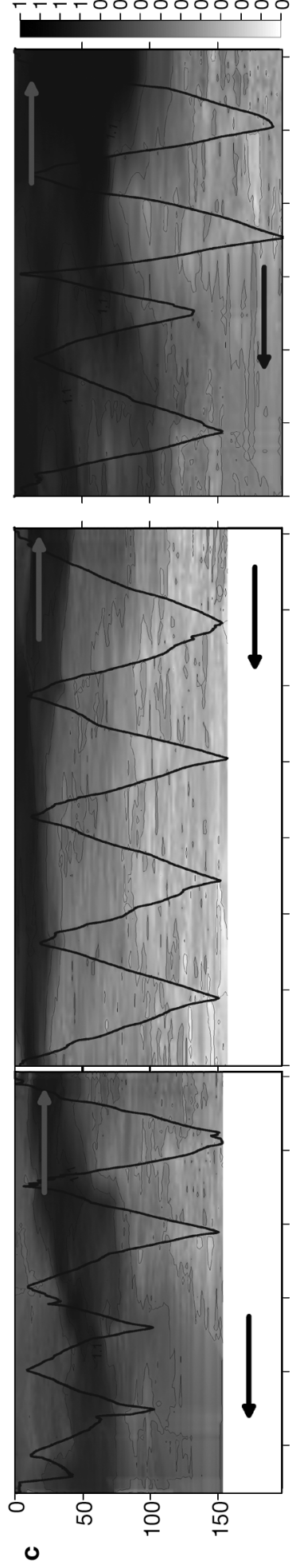

Depth (m)
氙

m.

Biomass $\left(\mathrm{g} \mathrm{m}^{-3}\right)$
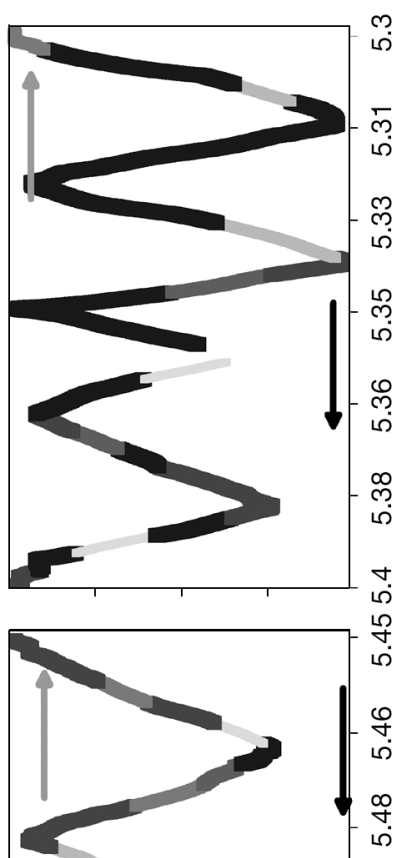

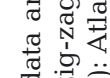
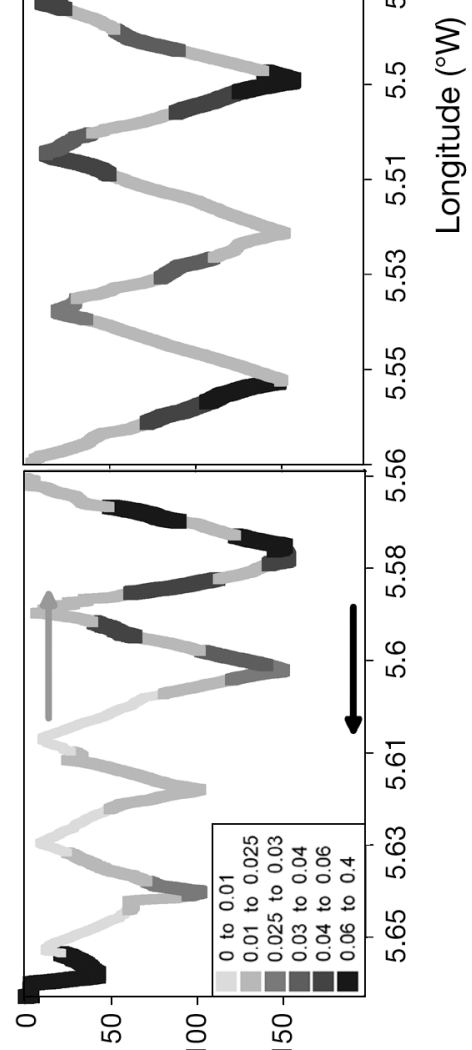

ठ
要

ज范

U

웜

\%

दี

寻

롤 을

100

'द प्ञ

의 유 :

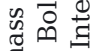

द्वा त्र

? U

놀 동

중 웡

过

ठृ

응

U웡

过 둥

㤩:

명 규응

웧

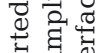

ब

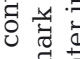

-

व

ठ립

ช

출

总要

을 돈

泀

窝:

ठิ

๑ 己

党

屯ै

령

लं

䗆 
Table 2. Mean physical and biogeochemical characteristics for each cast. Parentheses: maximum and minimum values

\begin{tabular}{|ccccc|}
\hline Cast & $\begin{array}{c}\text { Chl } a \\
\text { concentration } \\
\left(\mathrm{mg} \mathrm{m}^{-3}\right)\end{array}$ & $\begin{array}{c}\text { Zooplankton } \\
\text { biomass } \\
\left(\mathrm{mg} \mathrm{m}^{-3}\right)\end{array}$ & & Salinity \\
\hline \multirow{2}{*}{1} & 0.83 & 83.4 & 37.1 & $\begin{array}{c}\text { Temperature } \\
\left({ }^{\circ} \mathrm{C}\right)\end{array}$ \\
& $(0.4-1.5)$ & $(0-421)$ & $(35.9-37.9)$ & $(13.5-18.6)$ \\
2 & 0.63 & 34.1 & 36.9 & 15.1 \\
& $(0.4-1.1)$ & $(8-93)$ & $(35.7-37.4)$ & $(14.0-19.1)$ \\
3 & 0.8 & 41.8 & 36.1 & 17.5 \\
& $(0.38-1.1)$ & $(4-270)$ & $(35.5-37.2)$ & $(14.2-20.3)$ \\
4 & 0.9 & 19.7 & 19.7 & 18 \\
& $(0.6-1.1)$ & $(6-45)$ & $(35.9-37.4)$ & $(14.7-20.4)$ \\
5 & 0.6 & 23.2 & 36.6 & 15.2 \\
& $(0-4)$ & $(6-70)$ & $(35.4-37.7)$ & $(13.8-20.2)$ \\
\hline
\end{tabular}

salps among them. There were also differences in the species composition of the dominant taxon between surface and deep samples. In the surface group, the most abundant families are, in descending order: Phaennidae, Euchaetidae, Metridinidae (genera Metridia and Pleuromamma [P. robusta]), Candaciidae (C. armata) and Eucalanidae. In the deep sample group, only Euchaetidae (genera Euchaeta) and Metridinidae (genera Metridia and Pleuromamma [P. robusta]) were found, with Euchaetidae the dominant family in a 15:1 ratio.

It is also noteworthy that the larger fraction of Cast 2 was mainly composed of free-floating individuals (as revealed by microscopy), with very few organisms immersed in a mucilaginous matrix (as seen in other samples, see 'Cast 4').

Table 3. Abundance (ind. $\mathrm{m}^{-3}$ ) of the 12 most abundant taxa in Cast 2. Samples are separated into different depths and size fractions $(>$ and $<1000 \mu \mathrm{m}$ ). Bold: the 3 most abundant taxa in each size fraction. Large copepods include the families Euchaetidae, Metridinidae (genera Metridia and Pleuromamma), Centropagidae, Candaciidae (C. armata), Calanidae and Eucalanidae; small copepods include the families Temoridae, Calanidae and Metridinidae (genus Metridia); medium copepods include the smallest families of calanoid copepods, such as Paracalanidae and Pseudocalanidae, as well as cyclopoid (Oithoniidae), poecilostomatoid (Oncaeaidae and Coricaeidae) and harpacticoid copepods; other taxa include larvaceans, barnacle larvae, mysids, annelids, isopods, amphipods, mollusc larvae and fish larvae

\begin{tabular}{|c|c|c|c|c|c|c|}
\hline \multirow[t]{3}{*}{ Taxon } & \multirow{2}{*}{\multicolumn{2}{|c|}{ Surface }} & \multirow{2}{*}{\multicolumn{2}{|c|}{ - Abundance (ind. $\mathrm{m}^{-3}$ ) }} & \multirow[b]{2}{*}{ Total } & \multirow[b]{2}{*}{ 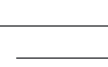 } \\
\hline & & & & & & \\
\hline & $>10^{3} \mu \mathrm{m}$ & $<10^{3} \mu \mathrm{m}$ & $>10^{3} \mu \mathrm{m}$ & $<10^{3} \mu \mathrm{m}$ & $>10^{3} \mu \mathrm{m}$ & $<10^{3} \mu \mathrm{m}$ \\
\hline Large copepods & 0.63 & 2.19 & 0.74 & 2.73 & 0.68 & 2.46 \\
\hline Small copepods & 0.39 & 22.73 & 0.16 & 15.25 & 0.28 & 18.99 \\
\hline Medium copepods & 0.74 & 261.05 & 0 & 195.76 & 0.37 & 228.40 \\
\hline Decapod and euphausiid larvae & 0.01 & 1.01 & 0 & 1.67 & 0.01 & 1.34 \\
\hline Ostracods & 0.06 & 22.99 & 0 & 21.10 & 0.03 & 22.04 \\
\hline Cladocerans & 0 & 0 & 0 & 0 & 0 & 0 \\
\hline Chaetognaths & 0.66 & 0.76 & 1.16 & 0.63 & 0.91 & 0.70 \\
\hline Euphausiids & 0.19 & 0 & 0.14 & 0 & 0.17 & 0 \\
\hline Appendicularians & 0 & 0 & 0 & 0 & 0 & 0 \\
\hline Siphonophores & 0 & 0 & 0.03 & 0 & 0.02 & 0 \\
\hline Salps & 0.16 & 0 & 0.08 & 0 & 0.12 & 0 \\
\hline Others & 0.84 & 11.54 & 0 & 7.62 & 0.42 & 9.58 \\
\hline
\end{tabular}

Table 4. Abundance (ind. $\mathrm{m}^{-3}$ ) of the 12 most abundant taxa in Cast 4. Samples are separated into different sectors and size fractions $(>$ and $<1000 \mu \mathrm{m}$ ). Bold: the 3 most abundant taxa in each size fraction. See Table 3 for copepod descriptions

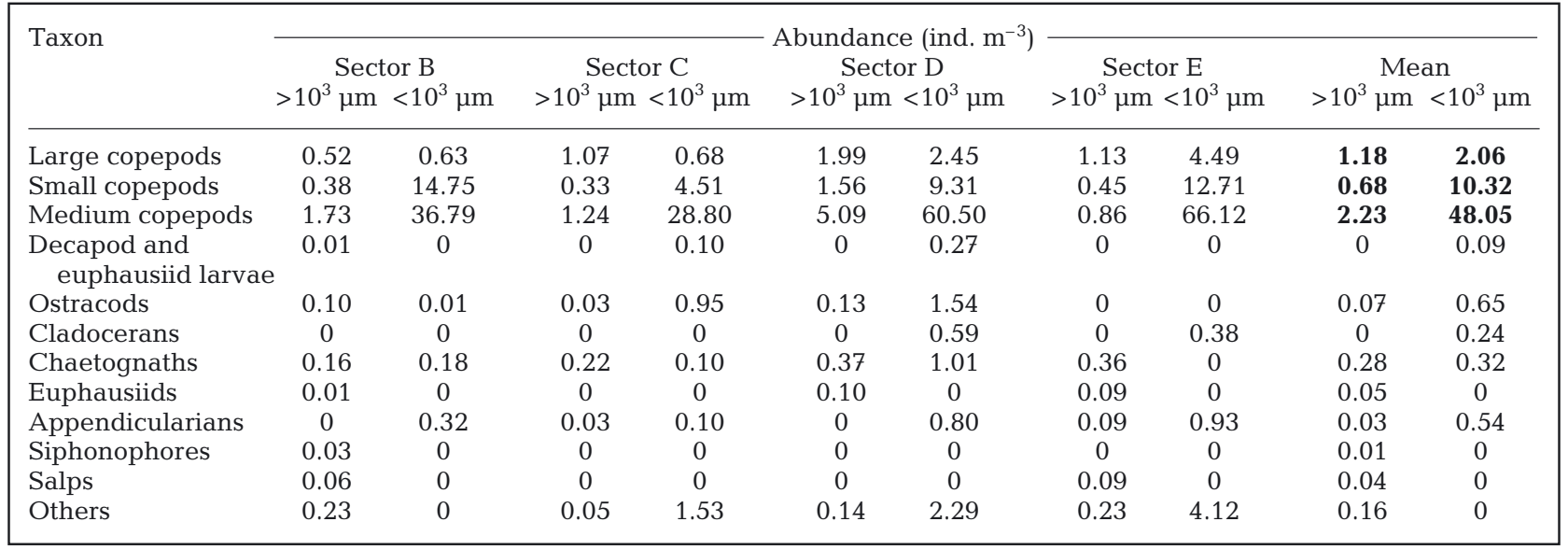




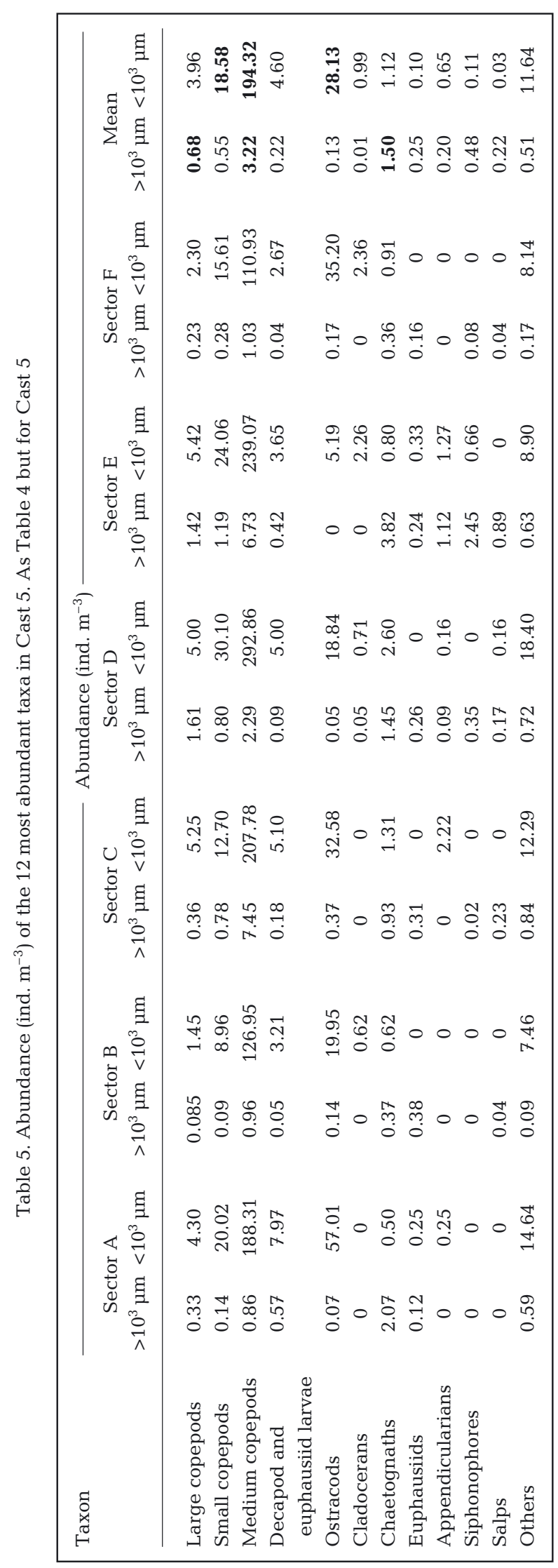

\section{Cast 4}

Fig. 5 depicts the distribution of temperature, salinity and chlorophyll concentrations during Cast 4, from surface to maximum sampling depth. Based on this information, this cast has been divided into 5 sectors (designated A to E, Fig. 5) with distinctive characteristics.

In Sector A, the temperature versus salinity (TS) diagram (Fig. 6a) shows the presence of NACW located around $100 \mathrm{~m}$ depth, marked by a salinity minimum in Fig. 5b. The transition between Sectors A and B is indicated by a strong horizontal salinity gradient (Fig. 5b) and a loss of the NACW signal (Fig. 6a). Sector B is characterized by a temperature gradient from surface to deeper waters while salinity is very constant from the surface down to $100 \mathrm{~m}$.

Between Sectors B and C, a new horizontal gradient in salinity values is present (Fig. 5b). The TS diagram of this sector (Fig. 6a) shows a generalized increase of salinity with respect to the 2 preceding sectors (minimum salinity of 36.4).

Sector D was located directly above the Camarinal Sill, and presents a marked horizontal salinity gradient (Fig. 5b), increasing from 36.5 up to 37.5 , and no vertical structure. The TS diagram of this sector is very distinctive, as 2 separated branches appear: one corresponds to the down-cast (left-hand scatters in Fig. 6a, constant low salinity) and the other to the up-cast of the LHPR profile (right-hand scatters in Fig. 6a, higher salinity in the upper layers).

Sector E starts with a sharp change in salinity conditions of the upper water layer, from a uniform value of 37.5 to a steep vertical gradient (Fig. 5b). A salinity minimum of 35.5 was observed at $50 \mathrm{~m}$ depth, indicating the presence of NACW and absence of MOW, as confirmed by the TS diagram (Fig. 6a).

Chlorophyll distribution (Fig. 5c) shows a DCM located around $50 \mathrm{~m}$ depth, extending from Sectors $\mathrm{C}$ to $\mathrm{E}$. In general, chlorophyll concentration was relatively low (average $=0.9 \mathrm{mg} \mathrm{m}^{-3}$, Table 2) and even the DCM is not very marked, with values ranging from 1 to $1.5 \mathrm{mg} \mathrm{m}^{-3}$.

Zooplankton biomass along Cast 4 was not correlated with any of the hydrological (temperature or salinity) or biogeochemical (chlorophyll) variables (Fig. 7a). No significant statistical correlation was found among temperature, salinity and chlorophyll $(p>0.05)$. The average biomass was particularly low for this cast (Table 2).

Composition of the zooplankton community during Cast 4 was analysed from 36 samples (Table 1) taken from Sectors B to E (Table 4). Very little differences were found between samples, indicating a very similar composition of the zooplankton community throughout the sampling path. Fig. $4 \mathrm{~b}$ shows the mean zooplank- 
Cast 2
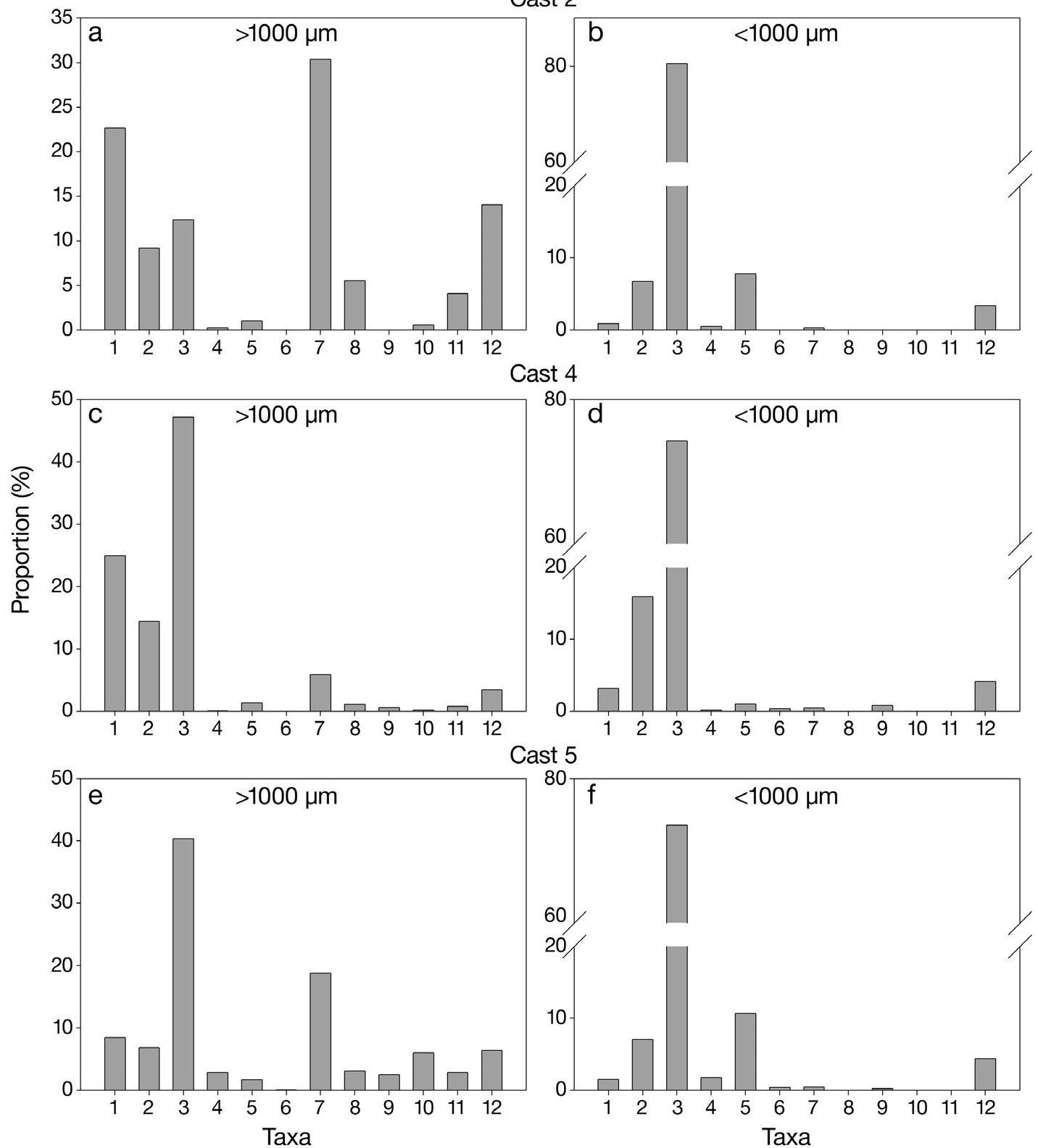

Fig. 4. Mean composition of zooplankton assemblage during Casts 2, 4 and 5 in the 2 size fractions analyzed. Taxa nos. - 1: Large copepods; 2: Small copepods; 3: Medium copepods; 4: Decapod and euphausiid larvae; 5: Ostracods; 6: Cladocerans; 7: Chaetognaths; 8: Euphausiids; 9: Appendicularians; 10: Siphonophores; 11: Salps; 12: Others (including larvaceans, barnacle larvae, mysids, annelids, isopods, amphipods, mollusc larvae and fish larvae)

ton abundance (intermediate plate), and also reveals that copepods again dominated the community, in terms of both biovolume and abundance.

However, there were significant differences $(\mathrm{p}<0.05)$ in zooplankton abundance between the samples of this cast (Fig. 7a). These differences reside within the taxonomic composition of the bigger fraction of those samples. In the samples with high zooplankton biomass, values exceed 100 ind. $\mathrm{m}^{-3}$ (Fig. 7a). Although the larger fraction was still dominated by copepods, it contained a variety of different organisms such as siphonophores, euphausiids and salps (which were dominant in terms of biovolume). On the other hand, some samples presented extremely low zooplankton biomass, with concentrations of individuals below 25 ind. $\mathrm{m}^{-3}$ (Fig. 7a). In these samples, the larger fraction comprised almost exclusively copepods at very low densities $\left(<0.1\right.$ ind. $\left.\mathrm{m}^{-3}\right)$. 

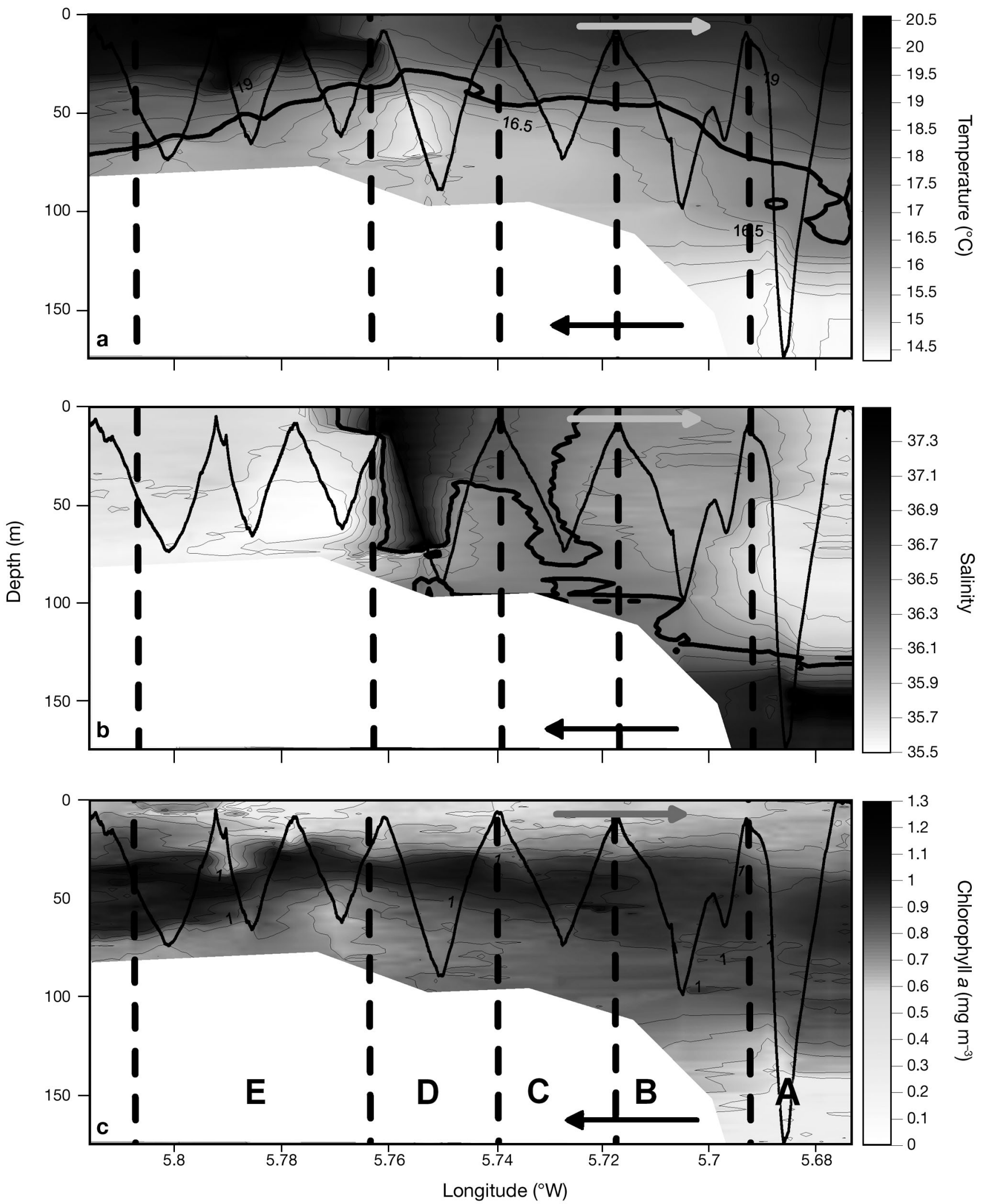

Fig. 5. Temperature $\left({ }^{\circ} \mathrm{C}\right)$, salinity and chlorophyll $a\left(\mathrm{mg} \mathrm{m}^{-3}\right.$; converted from fluorescence data) distributions during Cast 4 . Grey arrows show water current direction and black arrows show sampling direction. Bold zig-zag line: depth of Cast. Bold isotherm $\left(17.5^{\circ} \mathrm{C}\right)$ : Surface Atlantic Water-North Atlantic Central Water interface; bold isohaline (37): Atlantic-Mediterranean Interface position. In Sector E, water flow velocity decreased and even changed direction (i.e. flowing eastward), as indicated in Fig. 2 


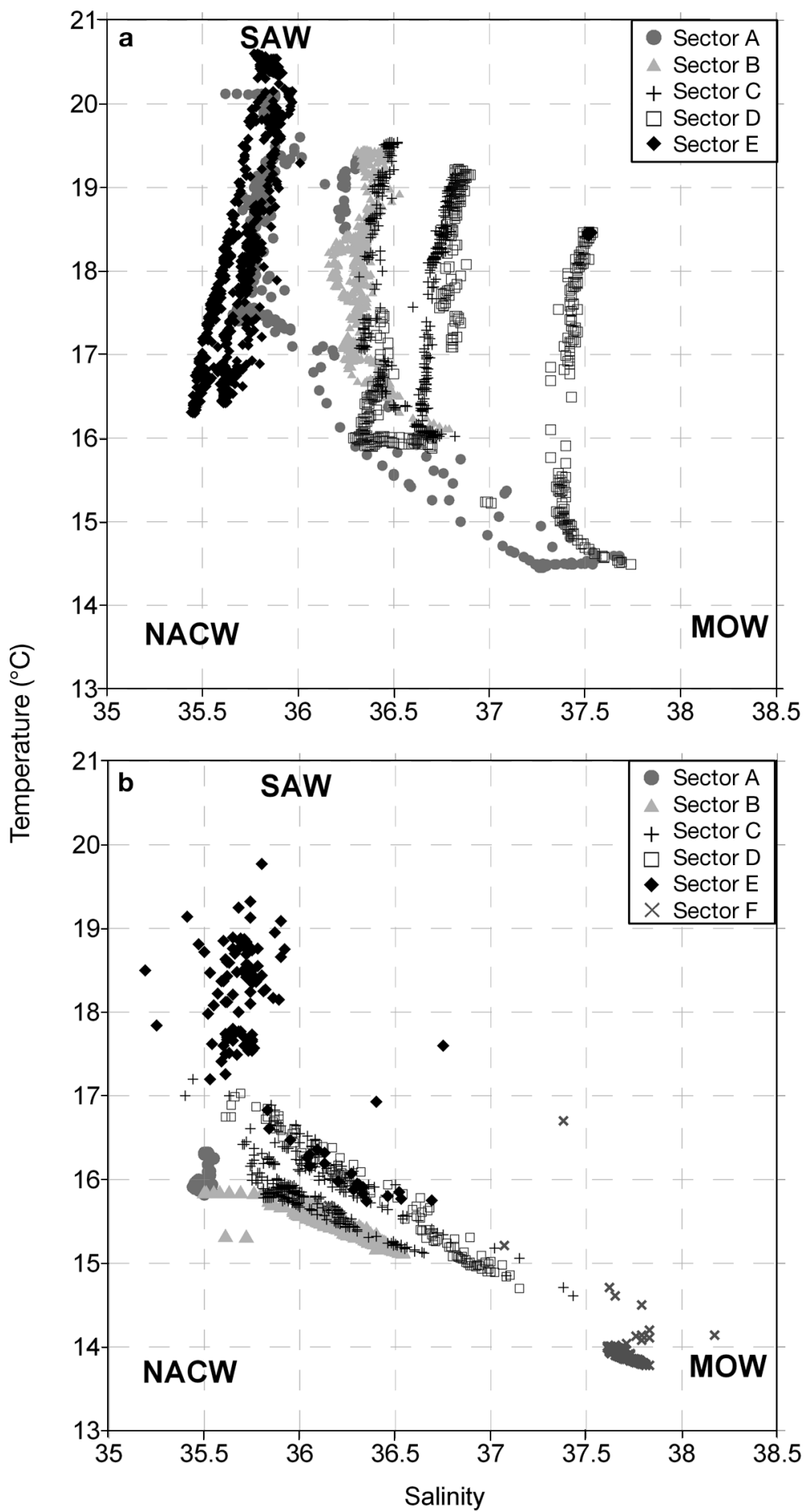

Fig. 6. Temperature versus salinity of the different sectors identified during (a) Cast 4 and (b) Cast 5

\section{Cast 5}

Cast 5 was performed entirely during the westward phase of the tidal cycle (Fig. 2) and a different strategy was used: the LHPR was hauled from east to west at a constant depth (nominal depth $100 \mathrm{~m}$ ).
Hydrological conditions during this cast are shown in Fig. 8. As in the previous casts, it has been divided into 6 sectors taking into account the hydrological conditions of the water column (mainly water masses). Sector A, situated west of the Camarinal Sill, is characterised by a constant temperature and salinity (Fig. 8), with the presence of NACW as shown in the TS diagram (Fig. 6b) and low values of chlorophyll throughout the sector (Fig. 8b). Further east, in Sector B, a gradient of both temperature and salinity was recorded with an increase in salinity and a decrease in temperature towards the eastern sectors (Fig. 8). The NACW signal disappears in the TS diagram (Fig. 6b), and even lower chlorophyll values were found (Fig. 8c).

The boundary between Sectors B and C is located directly over the Camarinal Sill and abrupt changes in the depth of the net occur in this transition zone, from $120 \mathrm{~m}$ at the end of Sector B to just $100 \mathrm{~m}$ at the beginning of Sector C (Fig. 8). An approximate vertical velocity of around $0.3 \mathrm{~m} \mathrm{~s}^{-1}$ can be calculated from this vertical displacement of the net. There was a slight increase in salinity values and a decrease in temperature with respect to the preceding sector (Fig. 8), which is also visible in the TS diagrams (Fig. 6b). The most dramatic change corresponds to the chlorophyll concentration, which was 10 times greater than in the preceding sectors (Fig. 8). The chlorophyll concentration recorded in Sector $C$ was the highest found during all the casts carried out in the strait (Table 2).

Between Sectors C and D, strong vertical oscillations of the LHPR net were again observed (Fig. 8), changing from 80 to $120 \mathrm{~m}$ very rapidly, with associated vertical velocities of around $0.4 \mathrm{~m} \mathrm{~s}^{-1}$. Corresponding with this oscillation, an abrupt change to colder and more saline waters was recorded (Fig. 8). The TS diagram for this sector (Fig. 6b) shows a mixture of only SAW and MOW. At the same time, chlorophyll concentration decreased very rapidly (Fig. 8) and almost disappeared.

At the beginning of Sector E, the LHPR again underwent sharp vertical movements and salinity values decreased, whereas temperature increased (Fig. 8). The TS diagram shows that there was only SAW in the LHPR path (Fig. 6b). As for the preceding sector, chlorophyll concentration remained very close to zero (Fig. 8). 


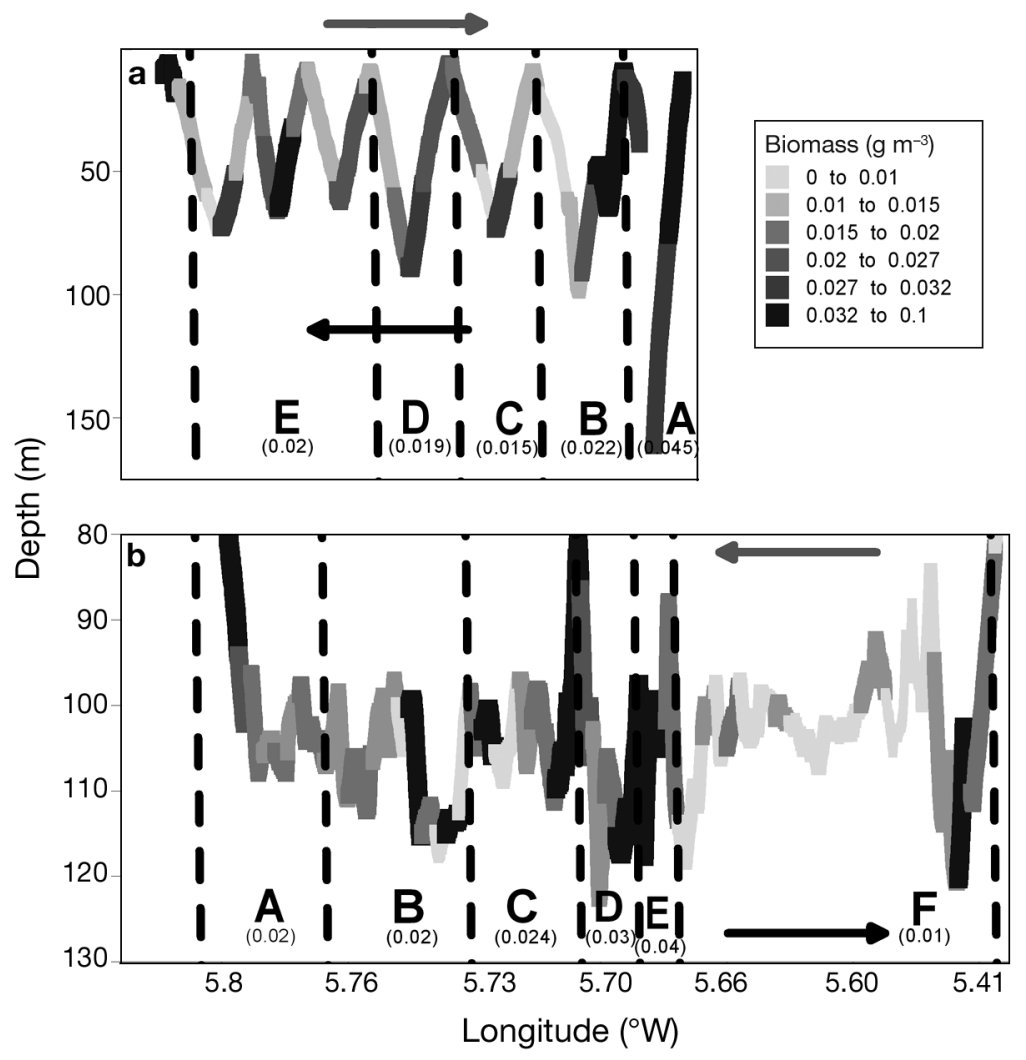

Fig. 7. Zooplankton biomass $\left(\mathrm{g} \mathrm{m}^{-3}\right)$ during (a) Cast 4 and (b) Cast 5. Parentheses: mean biomass concentrations in each sector. Grey arrows show water current direction and black arrows show sampling direction

Finally, in Sector F (which starts also with a severe oscillation of the LHPR), water composition changed. The salinity increased and the temperature decreased (Fig. 8), indicating that only MOW was present in this zone (Fig. 6b). No changes in chlorophyll concentration were detected, and the values remained very low.

During this cast, zooplankton biomass tended to accumulate in the transition zones between the different sectors defined previously (Fig. 7b). The density was greater in those transition zones characterised by marked horizontal gradients in salinity and/or temperature (such as the Sector C-D and D-E boundaries). The average zooplankton concentration in the upper $150 \mathrm{~m}$ in samples taken during daytime (Casts 4 and 5) shows no statistically significant difference (Student's $t$-test, $t=1.15, \mathrm{p}>0.1$ ) with respect to the corresponding concentration during the night (Casts 1, 2 and 3; Table 2).

Composition of the community by taxon during this last cast shows considerable differences in the various sectors, and is unlike the composition found in Casts 2 and 4 (Fig. 4). Although copepods were still the most important group in the smaller fraction, there were a number of different taxa showing increased abundance, such as ostracods, decapod larvae, etc. in the larger fraction (Fig. 4, Table 5).
This cast revealed sharp differences in the taxonomic composition of the samples between the different sectors (Table 5). Within the smaller size fraction, the second most abundant group (ostracods) varied considerably between sectors, accounting for $20 \%$ in Sectors A and $F$ (the first and last sampled) and decreasing to $<2 \%$ in Sector E. In the vicinity of the Camarinal Sill (Sectors C and D), groups such as siphonophores, salps and larvaceans (Appendicularia) were more abundant than in the rest of the cast, in both the larger and smaller fractions (Table 4). Mucilaginous material was present in the samples from Sectors C, D and E.

\section{DISCUSSION}

Results from the present study confirm the importance of physical forcing on biogeochemical distributions within the main channel of the Strait of Gibraltar as already pointed out in several studies (Gómez et al. 2001, 2004, Echevarría et al. 2002, Macías et al. 2006, 2007, 2008).

We had the opportunity of sampling the entire channel of the strait within $12 \mathrm{~h}$. This gave us, for the first time, a quasi-synoptic description of the spatio-temporal distribution of zooplankton in this area. Also, the most dynamic area of the entire strait (the Camarinal Sill sector) was sampled at 2 very different phases of the tidal cycle and internal wave development. This made it possible to relate the hydrological environment to the biogeochemical signatures recorded during each cast.

\section{Characteristics of the main channel of the strait}

From the 3 first casts, we have been able to study the characteristics of the along-strait flux and its effects on the biological pattern in the eastern sector of the main channel of the strait. Previous studies (e.g. Macías et al. 2006, 2008) have described a relationship between the presence of the internal waves at the AMI and high levels of chlorophyll in the eastern sector of the strait. In Cast 1, the same relationship can be appreciated, with an increased chlorophyll concentration coinciding with a sharp rise of the AMI (Fig. 3), which may be related to internal wave generation over the Camarinal Sill during the preceding tidal cycle (Farmer \& Armi 1986). In the data from Cast 1, zooplankton biomass 


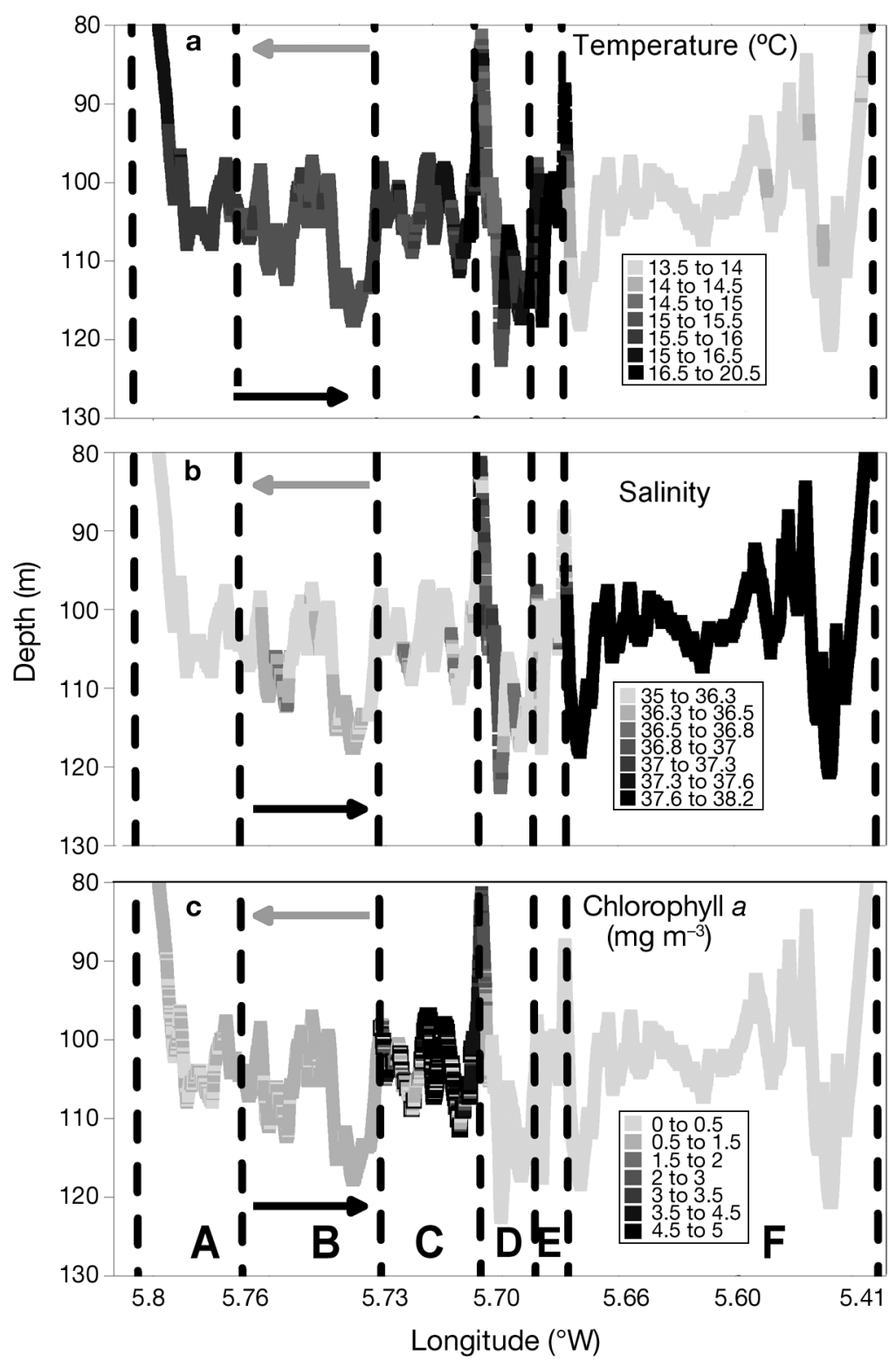

Fig. 8. Temperature $\left({ }^{\circ} \mathrm{C}\right)$, salinity and chlorophyll a $\left(\mathrm{mg} \mathrm{m}^{-3}\right.$; converted from fluorescence data) distributions during Cast 5. Grey arrows show water current direction and black arrows show sampling direction. was also partially correlated with chlorophyll values (Fig. 3), which could indicate that zooplankton are actively controlling their vertical position in order to be located within zones likely to present high densities of prey. Another possible explanation is that the same physical processes that shape phytoplankton distributions (i.e. divergences and convergences of internal waves) are also controlling zooplankton patterns (see discussion below about Cast 5 results).

When internal waves are not detected (e.g. during Casts 2 and 3), the chlorophyll levels are generally low and a DCM appears to only be associated with the
SAW-NACW interface, as previously described by Macías et al. (2008). In this case, zooplankton do not present any apparent spatial pattern (Fig. 3), and their taxonomic composition (Table 3 ) is very similar in the surface and deep samples, indicating that DVM does not seem to be sorting the community, at least down to the sampled depth.

\section{The Camarinal Sill}

Casts 4 and 5 permit a detailed study of the process of generation and intensification of the internal waves over the main sill of the strait.

\section{Conditions before internal wave development}

At the beginning of Cast 4, the tide was ebbing (Fig. 2) and the AMI was found at greater depth (right side of Fig. 5) with a clear signal of NACW (Fig. 6a) corresponding to an greater eastward flow (Lacombe \& Richez 1982, Macías et al. 2008). The shift in the tidal condition occurred about halfway through Cast 4 (Fig. 2). This increased the westward flow and caused the vertical shift of the AMI to a shallower depth, which interrupted the NACW flow, as observed in the western section of Cast 4 (Fig. 5) and corroborating previous data (Gómez et al. 2004, Macías et al. 2008).

Phytoplankton distribution during Cast 4 can be analysed within the framework of a model of current- plankton interactions developed by Franks (1992) for frontal areas. Following this model, when a divergent (horizontally) flux is present in a frontal zone, the plankton tends to show accumulation in a horizontal band which crosses the pycnoclines. In this case it has been postulated that a surface divergent area could appear between the Camarinal Sill and the Tarifa Narrows (see Fig. 1), coinciding with the tidal reversion (Izquierdo et al. 2001, Macías et al. 2007). East of Tarifa, where the strait narrows (Fig. 1), the surface layer flows eastward throughout the tidal cycle. Further west, the surface layer reverses its direction and flows to the west some $4 \mathrm{~h}$ before the highwater time (Macías et al. 2007). The surface divergence thus induced forces the deep waters to rise 
vertically which accounts for the shallow depth of the AMI recorded halfway through Cast 4 (Fig. 5). Horizontal advection of coastal waters from either the south or the north coast of the Strait, or both, may also compensate the surface divergence (see Macías et al. 2007, 2008).

Phytoplankton distribution during this Cast 4 is compatible with that predicted by the Franks (1992) model, since a high chlorophyll band is situated at about $50 \mathrm{~m}$ depth from Sectors B to D (Fig. 5c). However, the average concentration during the entire cast is quite low (0.9, Table 2), corresponding to a divergent situation. This same hydrological condition could be responsible for the decrease in the zooplankton biomass recorded during Cast 4 (Table 2, Fig. 7a). As these organisms possess swimming capabilities, the Franks (1992) model predicts an effect different from the one observed for phytoplankton. In this case, a progressive reduction of the population density from the point of divergence is expected, with the faster swimmers located further from that point. This was observed in our data, as mean zooplankton concentration was very low over the sill (Sector C), but was higher to the west and east (Fig. 8a). In almost all the samples from this cast, the dominant organisms were copepods of the genus Othiona (Fig. 4), which has a relatively slow swimming speed (0.4 $\mathrm{mm} \mathrm{s}^{-1}$; Yamasaki \& Squires 1996). Larger and faster swimmers like chaetognaths (swimming speeds of 1 to $2 \mathrm{~cm} \mathrm{~s}^{-1}$; Mutlu 2006), large euphausiids and siphonophores (30 $\mathrm{cm} \mathrm{s}^{-1}$; Bone 2005) were found only in the samples from Sectors B and E (the furthest from the area of divergence; Table 4).

However, another possible explanation for this zooplankton reduction could be the DVM pattern. Cast 4 was carried out very early in the daytime when zooplankters often migrate to deeper areas. DVM is a common behavior of most zooplankton groups, which spend the nighttime at the surface and descend to depth at dawn (Miller 2004). The assumed motivation for this behavior is to minimize the risk of predation, which is greater during daytime, and to feed on phytoplankton during the night. However, as stated previously, DVM does not seem to be a very important mechanism for the vertical distribution of zooplankton, since the average concentration of zooplankton in the upper $150 \mathrm{~m}$ during nighttime (Casts 1-3) and daytime (Casts 4 and 5) are not statistically different. Therefore, the vertical distribution of zooplankton seems to be more the result of physical forcing than migration patterns.

Internal waves are hydrological phenomena considered particularly important for zooplankton distribution patterns in many different places. For example, they may be important in the settling of invertebrate larvae on the seabed in coastal zones (e.g Pineda 1991,
1994) or in changing DVM patterns in frontal regions (Queiroga et al. 2007). An interruption of the DVM has been observed in other systems, such as convergence zones, where a continuous sound scattering layer has been reported in the upper water column throughout the day (Owen 1981, Wishner \& Allison 1986, Fielding et al. 2001). Vertical migration is, hence, altered by a conjunction of physical and biological factors that make it more profitable for the consumer to stay in front regions. Like the systems in these previous studies, the Strait of Gibraltar shows periodic episodes of convergence and surface enrichment as a consequence of the internal waves over the Camarinal Sill (Macías et al. 2006). Such phenomena lead to increased food availability. This could compensate zooplankton for losses due to more intense predation during the daytime. In this particular system, the coexistence of a surface current and a deep counter-current has been also cited as a mechanism for zooplankton to maintain their horizontal position by changing their vertical location within the water column (Gómez et al. 2001). More sampling is needed to detect the possible existence of DVM and to elucidate its intraspecific importance. Continuous recording during $24 \mathrm{~h}$ in fixed locations to cover the whole light cycle and avoid spatial heterogeneity would be particularly useful.

\section{Conditions during internal wave development}

Finally, when the Camarinal Sill area was again sampled during Cast 5, the hydrological conditions were substantially different, because the tidal current was westward during the entire cast (Fig. 2). In this phase of the tidal cycle and with enough tidal amplitude (westward velocities $>1 \mathrm{~m} \mathrm{~s}^{-1}$ ), internal waves are created along the AMI by the interaction of tidal currents and sill topography (Armi \& Farmer 1988, Bruno et al. 2002). Fig. 2 shows that this cast started just as the internal waves were beginning to be generated (according to the previous criteria) and lasted until shortly before the release of the waves, which happens again at a current velocity of approximately $1 \mathrm{~m} \mathrm{~s}^{-1}$ after the maximum flow westwards (Vázquez et al. 2008).

The presence of internal waves induces the creation of alternating bands of surface convergence and divergence which can control the distribution of suspended material including phyto- and zooplankton (Haury et al. 1979, Pineda 1999). Internal waves can also provoke intense interfacial mixing between Atlantic and Mediterranean waters (Gascard \& Richez 1985, Bray et al. 1995, Macías et al. 2007). Together all these processes could have influenced the biogeochemical patterns found in Cast 5. 
The presence of the internal waves throughout this entire cast is revealed by the oscillation of the LHPR at the sector boundaries (Fig. 8), since the sampling strategy in this cast was to maintain the net at a constant depth of around $100 \mathrm{~m}$. A schematic representation of the crest and trough of the internal waves during Cast 5 is presented in Fig. 9, constructed from the differential vertical movements of the LHPR. In this scheme the maximum vertical velocities (around $0.4 \mathrm{~m} \mathrm{~s}^{-1}$ ) are associated with transitions between trough and crest and coincide with the sectors boundaries defined in Fig. 7 . These results agree well with previous estimates based on predictions using numerical models and on direct current observations (Vázquez et al. 2006). The distribution expected was a symmetrical accumulation of zooplankton biomass above the troughs and below the crests of the internal waves. Since the convergencedivergence processes were actually taking place during the sampling, the accumulation recorded was higher towards the end of the cast (darker accumulation areas on the right-hand side of Fig. 9).

Sector C of Cast 5 coincides with Sector C of Cast 4 and is located directly over the sill (Fig. 1) or slightly westward. If the divergent processes do occur, as proposed above it is precisely in this area where they will be most likely (Macías et al. 2007, 2008). During Cast 5, a high chlorophyll concentration (Fig. 8) was found in this sector, while during Cast 4 this concentration was extremely low (Fig. 5). The fact than only a few hours passed between one cast and the next (insufficient time for in situ growth) and the presence of macroalgae debris (genus Plocamium) in the samples of this sector in Cast 5 are two factors suggesting that the hypothesis of lateral advection of chlorophyll-rich coastal areas is very likely. This is also supported by the intermediate values of salinity and temperature recorded in Sector C (Fig. 8), which match well with the presence of partially mixed waters from the coastal and shallower sectors (Navarro \& Ruiz 2006, Macías et al. 2007). The steep horizontal gradients of temperature and salinity between Sectors C and D impede the propagation of this chlorophyll patch eastward. The effect is to pack individuals together and concentrate the phytoplankton in a reduced area, making the chlorophyll concentration in the other sectors virtually zero (Fig. 8).

The effect of zooplankton biomass accumulation in frontal areas is a well-known phenomenon (Barange et al. 1998, Simpson et al. 1982, Shanks et al. 2000), and in the present study a higher maximum concentration of zooplankton was found in Cast 5 than in Cast 4 (Table 2). The accumulation in a frontal area predicted from modeling studies (e.g. Franks 1992) suggests that zooplankton concentration should be $<2$ times its normal values, which matches very well with the values observed the present study (Fig. 7).

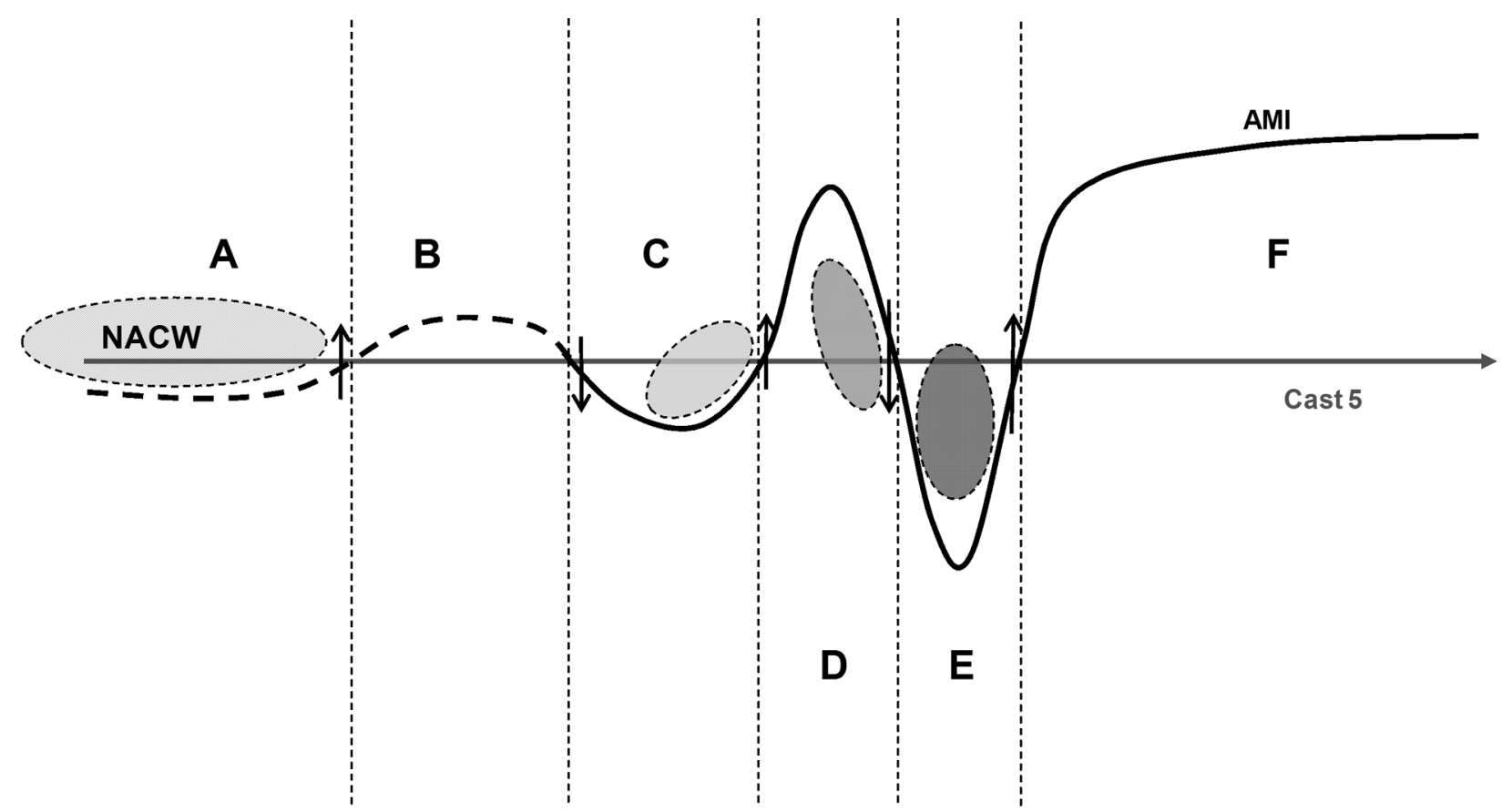

Fig. 9. Schematic representation of internal wave development during Cast 5 inferred from the vertical movement of the Longhurst-Hardy Plankton Recorder. Vertical arrows represent zones of stronger upward (downward) movement which usually happens between crest and trough (trough and crest) and coincides with sector limits (from Fig. 7). Grey areas are preferential accumulation zones for plankton biomass (darker grey indicates higher accumulation). NACW: North Atlantic Central Water; 
Within Cast 5, sharp differences in zooplankton biomass distributions were found between sectors (Fig. 7b, Table 5). Maximum concentrations appear situated over the wave trough (see Fig. 9) and below the wave crest (Sectors C, D and E; Fig. 7b), as predicted by the model of Lennert-Cody \& Franks (1999). However, not only biomass distribution was affected by the internal waves, but also taxonomic composition (Munk et al. 2003).

In the present study, larger organisms (that are likely better swimmers) appear in the samples from Sectors D and $E$, induced by the presence of the arrested internal waves in this region, while ostracods with lower swimming velocities decrease in abundance from Sectors A to $E$, but increase again in Sector $F$ where the effects of internal wave generation are no longer felt.

The Strait of Gibraltar is reported to be a region with high abundance of seabirds, high-level predators and marine mammals, and this abundance has been associated with the strategic position of the strait between 2 marine basins and 2 continents (as a natural pathway for large-scale migration). However, the characteristics of its marine environment may also partially explain those particular trophic features. For example, the accumulation of biomass of a size suitable for consumption by higher trophic levels (such as zooplankton) is of vital importance for the dynamics and structure of the marine food web. Seabirds and top-predator fish (i.e. tuna, swordfish, etc.) have been reported to accumulate on oceanic fronts (Russell et al. 1999) following higher zooplankton abundance in such areas. Furthermore, marine mammals are usually found in systems where physical forcing permanently reinforces primary and secondary production (Fiedler 2002). As both these processes take place in the strait, they could partially explain the abundance of all these high trophic-level organisms.

We have presented evidence of intense coastalchannel interactions in the Camarinal Sill region, and have discussed how the combined presence of such processes with the internal waves created over the sill could also explain the spatio-temporal pattern of zooplankton biomass and its distribution. These patterns could also be part of the explanation of the special food web structure in the pelagic realm of the Strait of Gibraltar which presents notable differences with respect to other nearby basins (Gulf of Cádiz and Alboran Sea).

Acknowledgements. This work was funded by the Spanish National Research Program, Project CTM2005-08142-C03-01 and CTM2008-06124. D.M. was supported by the Spanish Postdoc Fellowship Program (contract no. EX2008-0394). Three anonymous reviewers greatly helped in increasing the quality of the manuscript.

\section{LITERATURE CITED}

Armi L, Farmer D (1988) The flow of Mediterranean Water through the Strait of Gibraltar. Prog Oceanogr 21:41-82

Barange M, Pakhomov EA, Perissinotto R, Froneman PW, Verheye HM, Taunton-Clark J, Lucas MI (1998) Pelagic community structure of the subtropical convergence region south of Africa and in the mid-Atlantic Ocean. Deep-Sea Res I 45:1663-1687

Bone Q (2005) Gelatinous animals and physiology. J Mar Biol Assoc UK 85:641-653

Boyra G, Irigoien X, Arregi I (2005) Plankton visual analyzer. Globec Int Newsl 11:9-10

> Bray NA, Ochoa J, Kinder TH (1995) The role of interface in exchange through the Strait of Gibraltar. J Geophys Res 100:10755-10776

Bruno M, Alonso JJ, Cózar A, Vidal J, Ruiz-Cañavate A, Echevarría F, Ruiz J (2002) The boiling-water phenomena at Camarinal Sill, the strait of Gibraltar. Deep-Sea Res II 49:4097-4113

Echevarría F, García-Lafuente J, Bruno M, Gorsky G and others (2002) Physical-biological coupling in the Strait of Gibraltar. Deep-Sea Res II 49:4115-4130

Farmer D, Armi L (1986) Maximal two-layer exchange over a sill and through the combination of a sill and contraction with barotropic flow. J Fluid Mech 164:53-76

> Fiedler PC (2002) The annual cycle and biological effects of the Costa Rica Dome. Deep-Sea Res I 49:321-338

> Fielding S, Crisp N, Allen JT, Hartman MC, Rabe B, Roe HSJ (2001) Mesoscale subduction at the Almeria-Oran front. II. Biophysical interactions. J Mar Syst 30:287-304

$>$ Franks P (1992) Sink or swim: accumulation of biomass at fronts. Mar Ecol Prog Ser 82:1-12

Frassetto R, Backus RH, Hays E (1961) Sound-scattering layers and their relation to thermal structure in the Strait of Gibraltar. Deep-Sea Res 9:69-73

García-Lafuente J, Vargas Domínguez JM (2003) Recent observations of the exchanged flows through the Strait of Gibraltar and their fluctuations at different time scales. Recent Res Devel Geophys 5:73-84

> García-Lafuente J, Vargas JM, Plaza F, Sarham T, Candela J, Basheck B (2000) Tide at the eastern section of the Strait of Gibraltar. J Geophys Res 105:14197-14213

Gascard JC, Richez C (1985) Water masses and circulation in the western Alboran Sea and in the Straits of Gibraltar. Prog Oceanogr 15:157-216

Gómez F, Echevarría F, García CM, Prieto L and others (2000) Microplankton distribution in the Strait of Gibraltar: coupling between organisms and hydrodynamic structures. J Plankton Res 22:603-617

Gómez F, Gorsky G, Striby L, Vargas JM and others (2001) Small-scale temporal variations in biogeochemical features in the Strait of Gibraltar, Mediterranean side-the role of NACW and the interface oscillation. J Mar Syst 30: 207-220

Gómez F, Gorsky G, García-Górriz E, Picheral M (2004) Control of the phytoplankton distribution in the Strait of Gibraltar by wind and fortnightly tides. Estuar Coast Shelf Sci 59:485-497

- Haury LR, Briscoe MG, Orr MH (1979) Tidally generated internal wave packets in Massachusetts Bay. Nature 278: 312-317

> Izquierdo A, Tejedor L, Sein DV, Backhaus JO, Brandt P, Rubino A, Kagan BA (2001) Control variability and internal bore evolution in the Strait of Gibraltar: a 2-D twolayer model study. Estuar Coast Shelf Sci 53:637-651

Krzanowski WJ (1998) Principles of multivariate analysis. A 
user's perspective. Oxford Press

Lacombe H, Richez C (1982) The regime of the Strait of Gibraltar. In: Nilhoul JCJ (ed) Hydrodynamics of semienclosed seas. Proceedings of the 13th International Liège Colloquium on Ocean Hydrodynamics. Elsevier Oceanography Series 34, Elsevier, Amsterdam, p 13-73

Lennert-Cody CE, Franks PJS (1999) Plankton patchiness in high-frequency internal waves. Mar Ecol Prog Ser 186: 59-66

Macías D, García CM, Echevarría F, Vázquez-Escobar A, Bruno M (2006) Tidal induced variability of mixing processes on Camarinal Sill (Strait of Gibraltar). A pulsating event. J Mar Syst 60:177-192

- Macías D, Martin AP, García-Lafuente J, García CM and others (2007) Mixing and biogeochemical effects induced by tides on the Atlantic-Mediterranean flow in the Strait of Gibraltar. An analysis through a physical-biological coupled model. Prog Oceanogr 74:252-272

Macías D, Lubian LM, Echevarría F, Huertas E, García CM (2008) Phytoplankton chlorophyll maxima and water mass interfaces: tidal induced dynamics in the Strait of Gibraltar. Deep-Sea Res I 55:832-846

Mann KH, Lazier JRN (1991) Dynamics of marine ecosystems: biological-physical interactions in the oceans. Blackwell, Boston, MA

Marine Zooplankton Colloquium 2 (2001) Future marine zooplankton research - a perspective. Mar Ecol Prog Ser 222: 297-308

Miller CB (2004) Numerical models: the standard form of theory in pelagic ecology. In: Miller CB (ed) Biological oceanography. Blackwell Science, Oxford, p 69-91

Minas HJ, Coste B, Le Corre P, Minas M, Raimbault P (1991) Biological and geochemical signatures associated with the water circulation through the Strait of Gibraltar and in the western Alboran Sea. J Geophys Res 96:8755-8771

Munk P, Hansen BW, Nielsen TG, Thomsen HA (2003) Changes in plankton and fish larvae communities across hydrographic fronts off West Greenland. J Plankton Res 25:815-830

Mutlu E (2006) Diel vertical migration of Sagitta setosa as inferred acoustically in the Black Sea. Mar Biol 149: 573-584

Navarro G, Ruiz J (2006) Spatial and temporal variability of phytoplankton in the Gulf of Cádiz through remote sensing images. Deep-Sea Res II 53:1283-1298

Owen RW (1981) Fronts and eddies in the sea: mechanisms, interactions and biological effects. In: Longhrust AR (ed)

Editorial responsibility: Hans Heinrich Janssen, Oldendorf/Luhe, Germany
The analysis of marine ecosystems. Academic Press, London, p 199-233

Parrilla G (1990) WOCE and the Gibraltar Experiment third objective. In: Pratt LJ (ed) The physical oceanography of sea straits. Kluwer, Dordrecht, p 237-242

> Pineda J (1991) Predictable upwelling and the shoreward transport of planktonic larvae by internal tidal bores. Science 253:548-551

Pineda J (1994) Spatial and temporal patterns in barnacle settlement rate along a southern California rocky shore. Mar Ecol Prog Ser 107:125-138

Pineda J (1999) Circulation and larval distribution in intertidal bore warm fronts. Limnol Oceanogr 44:1400-1414

> Queiroga H, Cruz T, dos Santos A, Dubert J and others (2007) Oceanographic and behavioural processes affecting invertebrate larval dispersal and supply in the western Iberia upwelling ecosystem. Prog Oceanogr 74:174-191

> Russell RW, Harrison NM, Hunt GL Jr (1999) Foraging at a front: hydrography, zooplankton, and avian planktivory in the northern Bering Sea. Mar Ecol Prog Ser 182:77-93

Shanks AL, Largier J, Brink L, Brubaker J, Hoof R (2000) Demonstration of the onshore transport of larval invertebrates by the shoreward movement of an upwelling front. Limnol Oceanogr 45:230-236

Simpson JH, Tett PB, Argotte-Espinoza ML, Edwards A, Jones KJ, Savidge G (1982) Mixing and phytoplankton growth around an island in a stratified sea. Cont Shelf Res 1:15-31

Valiela I (1995) Marine ecological processes, 2nd edn. Springer, New York

> Vázquez A, Stashchuk N, Vlasenko V, Bruno M, Izquierdo A, Gallacher PC (2006) Evidence of multimodal structure of the baroclinic tide in the Strait of Gibraltar. Geophys Res Lett 33:L17605. doi:10.1029/2006GL026806

Vázquez A, Bruno M, Izquierdo A, Macías D (2008) The effect of meteorologically forced subinertial flows on internal waves generation at the main sill of the Strait of Gibraltar. Deep-Sea Res I 57:1277-1283

> Wiebe PH, Benfield MC (2003) From the Hensen net toward a four-dimensional biological oceanography. Prog Oceanogr 56:7-136

Wishner KF, Allison SK (1986) The distributions and abundance of copepods in relation to physical structure of the Gulf Stream. Deep-Sea Res 33:705-731

> Yamazaki H, Squires KD (1996) Comparison of oceanic turbulence and copepod swimming. Mar Ecol Prog Ser 144: 299-301

Submitted: August 10, 2009; Accepted: March 1, 2010

Proofs received from author(s): May 17, 2010 